\title{
Detection of free radicals in low-temperature gas-grain reactions of astrophysical interest
}

\author{
R. A. Zhitnikov and Yu. A. Dmitriev \\ Ioffe Physico-Technical Institute, 26 Politekhnicheskaya, St. Petersburg 194021, Russia
}

Received 15 October 2001 / Accepted 20 February 2002

\begin{abstract}
For laboratory detection and investigation of free radicals which often appear in chemical reactions of astrophysical interest either as important intermediate or as final products, we pioneered the use of the electron paramagnetic resonance (EPR) technique, which is very effective in observing these substances. This has allowed both formyl ( $\mathrm{HCO}$ and $\mathrm{DCO})$ and methyl $\left(\mathrm{CH}_{3}\right.$ and $\left.\mathrm{CD}_{3}\right)$ free radicals to be detected in a sequence of lowtemperature gas-grain reactions of $\mathrm{H}$ and $\mathrm{D}$ atom addition in solid $\mathrm{CO}$. The solid samples subjected to the EPR study were obtained by simultaneous independent deposition of CO molecules and either $\mathrm{H}$ or $\mathrm{D}$ atoms on the substrate cooled to liquid helium temperatures. The sequence of the $\mathrm{H}$-atom addition gas-grain reactions in solid CO is acknowledged to be among the fundamental processes responsible for the synthesis of organic molecules in interstellar cloud dust grains. The present observation of the above free radicals confirms that the solid-state gasgrain sequence of the reactions is efficient at low temperatures; it also suggests that there should be considerable concentrations of formyl and methyl radicals in the ISM. Another study concentrated on the formation of ethyl free radicals $\left(\mathrm{C}_{2} \mathrm{H}_{5}\right)$ in a low-temperature gas-grain reaction of $\mathrm{H}$-atom abstraction from a $\mathrm{C}_{2} \mathrm{H}_{6}$ molecule by free $\mathrm{H}$-atom in solid $\mathrm{CH}_{4}$. These experiments were carried out by deposition onto a substrate, cooled by liquid helium, of a flow of $\mathrm{CH}_{4}$ molecules containing a small amount of impurities such as ethane molecules $\left(\mathrm{C}_{2} \mathrm{H}_{6}\right)$, free $\mathrm{H}$-atoms and $\mathrm{CH}_{3}$ radicals formed in a discharge in a pure gaseous methane. EPR spectra of $\mathrm{CH}_{3}$ radicals, H-atoms, and $\mathrm{C}_{2} \mathrm{H}_{5}$ radicals matrix-isolated in solid $\mathrm{CH}_{4}$ were detected. The relative concentrations of the radicals were found to depend on the experimental conditions. The abstraction reaction, $\mathrm{C}_{2} \mathrm{H}_{6}+\mathrm{H} \rightarrow \mathrm{C}_{2} \mathrm{H}_{5}+\mathrm{H}_{2}$, took place in $\mathrm{CH}_{4}$-ice.
\end{abstract}

Key words. astrochemistry - molecular processes - methods: laboratory - ISM: dust, extinction - ISM: molecules ISM: atoms

\section{Introduction}

In interstellar clouds, comets and the atmospheres of solar planets, a number of organic compounds have been observed. In dense interstellar clouds, starlight is largely excluded and gas-phase ion-molecule reactions become less important for the formation of interstellar molecules. This suggests that interstellar dust grains play an important role for the chemical evolution in the cold dark interstellar medium. In order to explain both the interstellar solid state reactions of the synthesis of organic molecules and their transformation and to verify the assumptions of plausible synthesis reactions, conditions were modeled, in a number of laboratories, which are similar to those in interstellar dust, cometary ices and planetary atmospheres. At these conditions, the products of the relevant low-temperature solid state reactions were studied

Send offprint requests to: R. A. Zhitnikov, e-mail: zhitnikv.mares@pop.ioffe.rssi.ru (e.g. Gerakines et al. 1995, 1996, 2000; Ehrenfreund et al. 1996, 1997, 1999; Hiraoka et al. 1995, 1998, 1999, 2000; Bernstein et al. 1995; Pendelton et al. 1999; Sandford et al. 2000). Of special interest is a modeling of gas-grain reactions involving hydrogen atoms (Hiraoka et al. 1995, 1998, 1999, 2000) and the products formed in the cometary and interstellar ice analogs with various impurities subjected to action by UV radiation, ion bombardment and others (Gerakines et al. 1995, 1996, 2000; Ehrenfreund et al. 1996, 1997, 1999; Bernstein et al. 1995; Pendelton et al. 1999; Sandford et al. 2000). For observation and study of such low temperature reactions in the laboratory, a variety of analytical methods: IR spectroscopy, massspectrometry, gas chromatography, nuclear magnetic resonance (NMR) is used (Gerakines et al. 1995, 1996, 2000; Ehrenfreund et al. 1996, 1997, 1999; Hiraoka et al. 1995, 1998, 1999, 2000; Bernstein et al. 1995; Pendelton et al. 1999; Sandford et al. 2000). Though they offer a number of advantages, these methods are of limited usefulness. 
Some of them (NMR, IR spectroscopy) are not sensitive enough, while other (mass-spectrometry) do not permit studying in situ and involve thermal desorption and heating of the sample, which may lead to the observation of products different from those in the initial lowtemperature reactions in the solid state sample. In the present study, we employed the electron paramagnetic resonance (EPR) method which makes it possible to observe and study, in situ and in real time, the products of low-temperature reactions at any temperature of the solid state sample. Very importantly, this method allows registration, more accurate identification and investigation of free radicals with unpaired electron spins which are frequent as intermediate products of such reactions. Moreover, the EPR method is a very sensitive one.

\section{Experimental procedure}

The solid samples under study are obtained by gas condensation on the thin-walled bottom of a quartz finger filled with liquid helium. Located at the center of the microwave cavity of the EPR spectrometer, the bottom is used as a substrate. Both the gas discharge and the matrix gas flow passing through a separate inlet tube to avoid the gas discharge can be cooled down to liquid nitrogen temperature. The products of radio-frequency gas discharge without intermediate feeding tubes are supplied directly onto the substrate in vacuum preventing their decay on the tube walls. Thus, the sample is obtained directly in the cavity of the EPR spectrometer, allowing an EPR observation of the sample during the condensation and a study of shortlived centres (e.g. free radicals) due to the gas discharge products.

The experimental set-up consists of a $3 \mathrm{~cm}$ EPR spectrometer with a microwave cavity cooled by liquid nitrogen vapor, a gas filling and purification system, a RF oscillator for exciting an electrodeless discharge, measuring instruments, and pumping facilities.

Figure 1 shows the major section of the experimental set-up: the microwave cavity of the $3 \mathrm{~cm}$ EPR spectrometer, the low-temperature gas discharge device and the substrate cooled by liquid helium, on which the sample is condensed.

Here, 1 is the cylindrical $\mathrm{H}_{011}$ - mode microwave cavity of the $X$-band EPR spectrometer, 2 is the bottom of quartz finger 3 , filled with liquid helium, and 4 is a waveguide. Bottom 2 of the quartz finger is a low-temperature substrate for the gases being condensed. An electrodeless $\mathrm{RF}$ gas discharge is excited in glass tube 5 with outlet 6 of $0.2-0.6 \mathrm{~mm}$ diameter. The matrix gas can be supplied to substrate 2 by glass tube 7 and further by quartz tube 8 inserted into the cavity (channel B). The end of quartz tube 8 is located close $(3 \mathrm{~mm})$ to bottom 2 of the quartz finger, which facilitates effective freezing out of the matrix gas.

Whole device presented in Fig. 1 is cooled externally with liquid nitrogen vapor $\left(\mathrm{LN}_{2}\right)$ and its temperature can be varied from 77 to $300 \mathrm{~K}$.

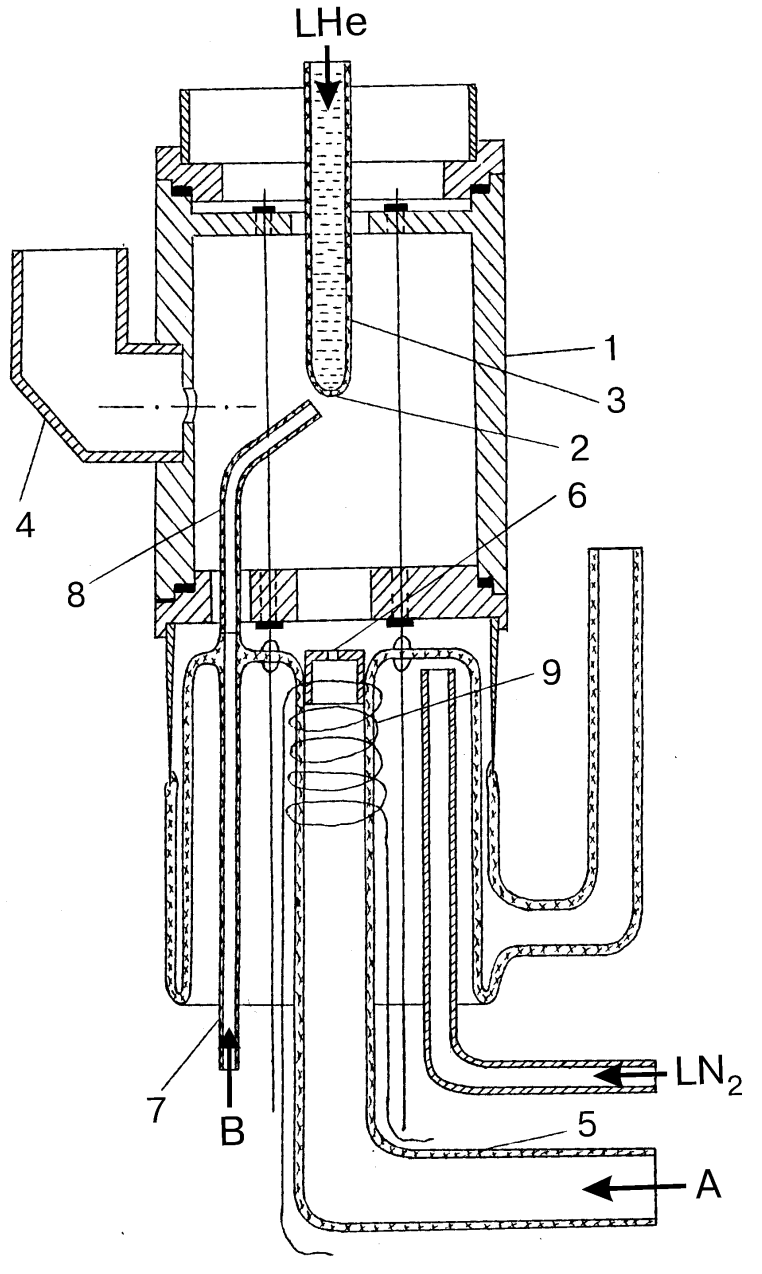

Fig. 1. The main part of the experimental set-up including the microwave cavity of the EPR spectrometer, the gas discharge system, the second gas inlet tube avoiding gas discharge, and the quartz finger cooled by liquid helium (LHe) with the sample condensed onto the bottom of the quartz finger as on a substrate (for notations see the text).

A RF (14-MHz) oscillator is used to sustain the discharge. The RF power is fed through a coaxial cable to coil 9 wound over the gas discharge tube 5 .

The experimental procedure is as follows. The gas in channel A is passed through the liquid-nitrogen-vaporcooled gas discharge tube 5, in which an electrodeless RF discharge is excited. Ground-state gas atoms or molecules, together with the gas discharge products pass through outlet 6 of discharge tube 5 into the evacuated cavity and reach bottom 2 of quartz finger 3 filled with liquid helium at $1.2-4.2 \mathrm{~K}$. Pure additional matrix gas, also cooled by liquid nitrogen vapor $\left(\mathrm{LN}_{2}\right)$, may be passed through tubes 7-8 (channel B), avoiding the gas discharge, onto the substrate. The gas from channel A is condensed together with discharge products onto substrate 2 at a temperature of 1.2-4.2 K either with or without the gas flux passing through channel B. In the present study, the sample deposition usually takes about 30-60 min. Upon completion of the deposition, the fluxes from channels A and B are switched off, and EPR spectra of the sample 

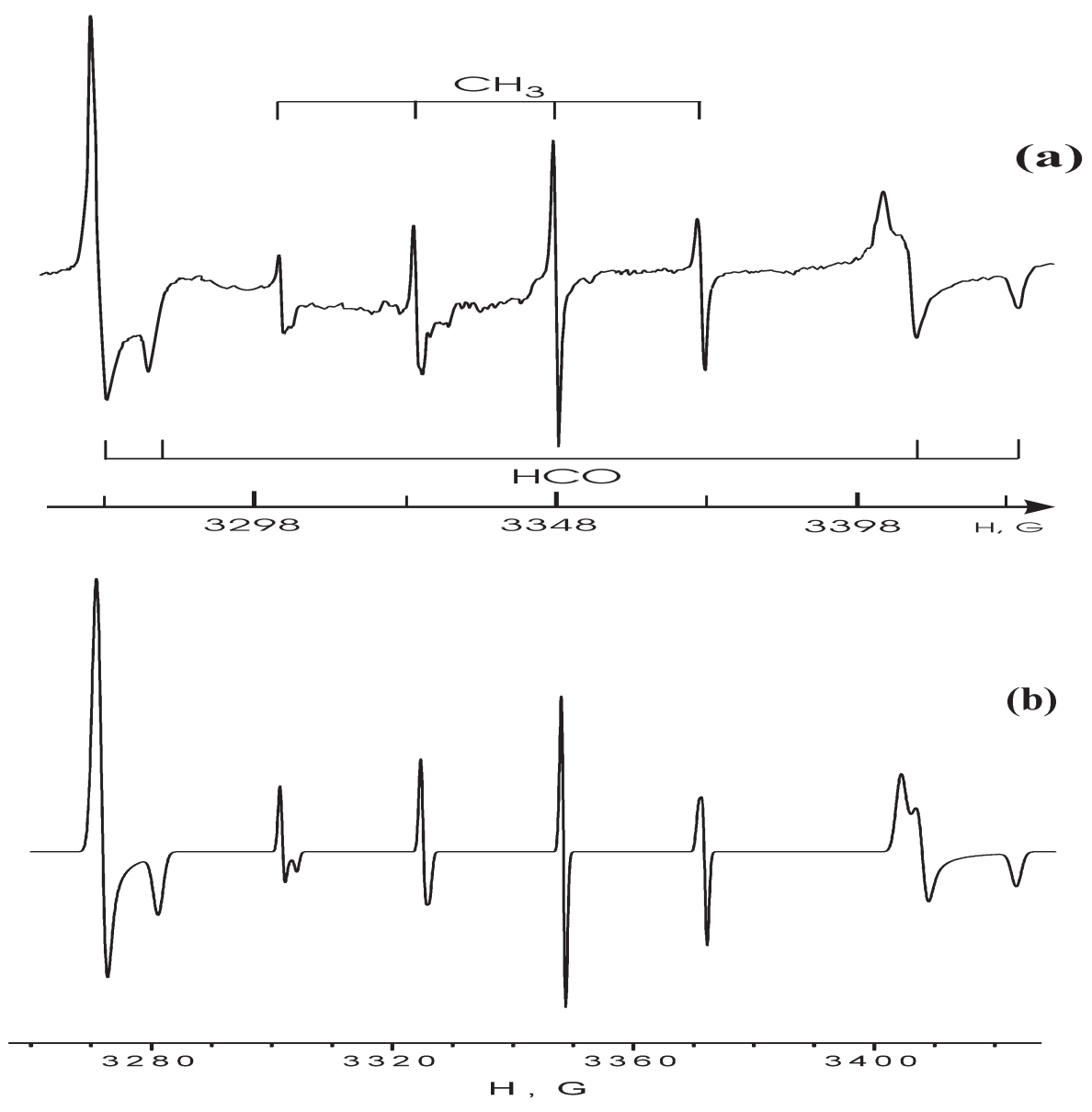

Fig. 2. a) The EPR spectrum of HCO and $\mathrm{CH}_{3}$ free radicals formed in a sequence of gas-grain $\mathrm{H}$-atom addition reactions in solid $\mathrm{CO}$ at $4.2 \mathrm{~K}$. The EPR resonance frequency $f_{\text {res }}=$ 9353.04 MHz. b) The simulated EPR spectrum for $\mathrm{HCO}$ and $\mathrm{CH}_{3}$ free radicals in solid CO. $f_{\text {res }}=$ 9353.0 MHz. (For details, see text).

are taken. While the sample was obtained and the spectra were recorded, the substrate temperature could be set to $1.2-4.2 \mathrm{~K}$ by pumping out the helium vapor from bath 3 .

The experimental procedure and set-up have been described in papers by Zhitnikov \& Dmitriev (1994, 1995).

\section{Gas-grain consecutive $\mathbf{H}$-atom addition reactions in solid $\mathrm{CO}$}

Stepwise low-temperature hydrogenation reactions taking place on and in interstellar dust grains are known to be among the fundamental processes responsible for the synthesis of organic molecules in interstellar clouds. In particular, the low-temperature consecutive gas-grain $\mathrm{H}$-atom addition reactions in solid $\mathrm{CO}$ are considered in (Hiraoka et al. 1998). Of these, the sequence of reactions of $\mathrm{H}$ atoms with $\mathrm{CO}$ is an important case:

$$
\begin{array}{rc}
\mathrm{CH}_{4} \leftarrow \mathrm{CH}_{3} & +\mathrm{OH} \rightarrow \mathrm{H}_{2} \mathrm{O} \\
& \uparrow \\
\mathrm{CO} \rightarrow \mathrm{HCO} \rightarrow \mathrm{H}_{2} \mathrm{CO} \rightarrow & \mathrm{CH}_{2} \mathrm{OH} \rightarrow \mathrm{CH}_{3} \mathrm{OH} \\
& \downarrow \\
& \downarrow \\
\mathrm{CH}_{4} \leftarrow \mathrm{CH}_{3} \leftarrow \mathrm{CH}_{2} & +\mathrm{H}_{2} \mathrm{O} .
\end{array}
$$

It is known that an exothermic reaction of the $\mathrm{H}$ atom with $\mathrm{CO}$ in spite of the energy barrier is liable to proceed even at low temperatures due to tunneling. This sequence of reactions of $\mathrm{H}$ atoms with solid $\mathrm{CO}$ was previously investigated in laboratory conditions by mass spectrometry (Hiraoka et al. 1998) which could record only closed-shell and stable molecules such as methane $\left(\mathrm{CH}_{4}\right)$, methanol $\left(\mathrm{CH}_{3} \mathrm{OH}\right)$, and formaldehyde $\left(\mathrm{H}_{2} \mathrm{CO}\right)$ among the reaction products. However, the observation of free radicals: $\mathrm{CH}_{2} \mathrm{OH}$, formyl $(\mathrm{HCO})$, methyl $\left(\mathrm{CH}_{3}\right)$, hydroxyl $(\mathrm{OH})$, and methylene $\left(\mathrm{CH}_{2}\right)$, which appear as intermediate products is of great importance for the confirmation and detailed investigation of this solid-phase process. Intermediate reaction products, such as free radicals, cannot be detected by mass spectrometry, but by electron paramagnetic resonance (EPR) they can be detected.

The present section is devoted to the detection and study of free radicals in the above sequence of lowtemperature reactions of $\mathrm{H}$ atoms with solid $\mathrm{CO}$ using EPR. The experimental procedure involved co-deposition of gaseous CO supplied through channel B (see Fig. 1) and a flow of molecular hydrogen gas-discharge products containing abundant $\mathrm{H}$ atoms from channel $\mathrm{A}$ onto a quartz substrate at 1.3-4.2 K. Normally, the deposition took $30 \mathrm{~min}$; after this $X$-band EPR spectra of the sample were recorded. Thus a process was simulated which is similar to the one what takes place in interstellar dust grains.

The experiments yielded the spectra shown in Fig. 2a. These spectra are due to $\mathrm{HCO}$ and $\mathrm{CH}_{3}$ radicals 
matrix-isolated in solid CO. The $\mathrm{HCO}$ spectrum is a doublet with a separation between the hyperfine components of $140 \mathrm{G}$ and $g=2.00$. The $\mathrm{CH}_{3}$ spectrum is a quartet with $g=2.00$ and an average separation between the adjacent lines of $23.5 \mathrm{G}$. The numbers and positions of the lines very closely match the known values of $\mathrm{HCO}$ (Adrian et al. 1962) and $\mathrm{CH}_{3}$ (Adrian et al. 1985), which strongly substantiates that they have been formed in the present experiments. This is the first occasion of the detection of free radicals in a process of gas-solid type where organic substances are synthesized. The observed $\mathrm{HCO}$ and $\mathrm{CH}_{3}$ EPR spectra indicate an anisotropy of these paramagnetic centers (trapped radicals) in solid CO. Figure $2 \mathrm{~b}$ shows a simulated EPR spectrum for $\mathrm{HCO}$ and $\mathrm{CH}_{3}$ free radicals trapped in a polycrystalline solid CO. The EPR spectra for formyl and methyl radicals were simulated from the following parameters for the hyperfine structure, $A$, tensors and $g$-factor tensors: for $\mathrm{HCO}$, $A_{x x}=132.89 \mathrm{G}, A_{y y}=136.32 \mathrm{G}, A_{z z}=142.11 \mathrm{G}, A_{y z}=$ $5.79 \mathrm{G}, g_{x}=2.0011, g_{y}=1.9997, g_{z}=1.9930$, a linewidth of $1.6 \mathrm{G}$ and Gaussian line shape were assumed (see also Adrian et al. 1962); for $\mathrm{CH}_{3}, A_{x x}=A_{y y}=A_{\perp}=23.50 \mathrm{G}$, $A_{z z}=A_{\|}=22.20 \mathrm{G}, g_{x}=g_{y}=g_{\perp}=2.0026, g_{z z}=g_{\|}=$ 2.0022 and a linewidth of $0.75 \mathrm{G}$ and the Gaussian line shape were assumed. The simulated spectrum in Fig. $2 \mathrm{~b}$ shows the concentration of $\mathrm{CH}_{3}$ radicals to be about $2 \%$ of the $\mathrm{HCO}$ concentration. This gives new information on the concentrations of the intermediate products in the Seq. (1).

The results lend support to the validity of the above sequence of hydrogenation reactions in solid $\mathrm{CO}$ which are likely to occur in the interstellar medium. After $\mathrm{H}_{2}$, $\mathrm{CO}$ is the most abundant molecule in dense interstellar clouds. The other free radicals, expected to be formed in this process, were not observed reliably in the present experimental conditions. These conditions are currently being changed (by increasing the substrate temperature and varying the condensation procedure) in order to be able to record these radicals. The radicals are hard to observe, probably because of a great difference in rate constants between reactions (tunneling for the most part) in Seq. (1). Such a difference would have the effect of decreasing the concentration of those intermediate products that are result of a reaction with a low rate constant and (or) hydrogenated with a high rate constant and vice versa.

In many studies it was experimentally confirmed (Hiraoka et al. 1995), that hydrogen atoms diffuse over long distances in solid matrices and take part in tunneling reactions in the temperature region of $4-20 \mathrm{~K}$. In contrast to mobile $\mathrm{H}$ atoms, the diffusion of atoms other than $\mathrm{H}$ and of molecules at cryogenic temperatures has not been reported so far. The high mobility of $\mathrm{H}$ atoms on solids suggests that hydrogen plays a major role in the solid state chemical evolution of dense clouds, i.e. they diffuse long distances on grain surfaces and in mantles and react with trapped and immobilized atoms and molecules to form hydrogenated products in the mantles. In the work by Hiraoka et al. (1995), the reactions between atomic hydrogen and nitrogen atoms trapped in an $\mathrm{N}_{2}$ matrix in the temperature range of $10-30 \mathrm{~K}$ were studied to check the possibility of ammonia synthesis in the grain mantles. It was concluded that $\mathrm{H}$ atoms migrated into the $\mathrm{N}_{2}$ matrix to a depth of at least $200 \mathrm{~N}_{2}$ monolayers and hydrogenated $\mathrm{N}$ atoms trapped in the $\mathrm{N}_{2}$ matrix (Hiraoka et al. 1995). A CO matrix is isoelectronic and very similar to a $\mathrm{N}_{2}$ matrix (their melting points $T_{\mathrm{m}}(\mathrm{CO})=68 \mathrm{~K}, T_{\mathrm{m}}$ $\left.\left(\mathrm{N}_{2}\right)=63 \mathrm{~K}\right)$.

The available data suggest that the Seq. (1) with the formation of $\mathrm{HCO}$ and $\mathrm{CH}_{3}$ radicals (Fig. 2a) may occur in our experiments as follows. The $\mathrm{CO}$ molecules from channel $\mathrm{B}$ as well as $\mathrm{H}_{2}$ molecules and $\mathrm{H}$ atoms from channel A, Fig. 1, simultaneously enter the sample surface. The $\mathrm{CO}$ flow is estimated to be an order of magnitude greater than that of $\mathrm{H}_{2}$ molecules, while $\mathrm{H}$ atoms constitute a portion of the $\mathrm{H}_{2}$ quantity; the temperature of all particles incident on the sample being in the range of 80 to $100 \mathrm{~K}$. For this reason there exists a steadily growing solid CO layer which traps hydrogen atoms. On and under the surface, all products of reactions (1) are immobilized, while the light hydrogen atoms trapped there are highly mobile and diffuse long distances taking part in the Seq. (1) of the H-atom addition to the intermediate products. This is the reason why the Seq. (1) yields not only the first intermediate product, $\mathrm{HCO}$, but also the $\mathrm{CH}_{3}$ radical as an intermediate product which is also observed in our experiments. This model is also supported by the fact that no EPR spectra of matrix-isolated H-atoms were observed, which testifies that nearly all trapped hydrogen atoms disappear through the Seq. (1), except for atoms which have escaped the surface or taken part in the recombination reaction to form the $\mathrm{H}_{2}$ molecule.

The fact that the $\mathrm{HCO}$ and $\mathrm{CH}_{3}$ spectra are really due to the Seq. (1) in solid CO (and not from, for example, the possible small $\mathrm{CH}_{4}$ impurity in the gaseous $\mathrm{H}_{2}$ discharge) was checked in additional experiments, where $\mathrm{D}_{2}$ was passed through the discharge zone instead of $\mathrm{H}_{2}$. Simultaneously, pure CO was fed through channel B. The spectra obtained in these runs, (Fig. 3a), are composed of only DCO and $\mathrm{CD}_{3}$ free radical spectra. No $\mathrm{HCO}$ or $\mathrm{CH}_{3}$ radicals are seen in Fig. 3a. When divided into two parts, these spectra coincide, respectively, with those of DCO obtained by Adrian et al. (1962) in photolysis experiments and of $\mathrm{CD}_{3}$ by Toriyama et al. (1979). Figure 3b shows a simulated EPR composite spectrum of the mixture of DCO and $\mathrm{CD}_{3}$ radicals trapped in a polycrystalline solid CO. The spectrum is a sum of two neat spectra for DCO and $\mathrm{CD}_{3}$ radicals in $\mathrm{CO}$ matrix shown in Figs. $3 \mathrm{c}$ and $\mathrm{d}$, respectively. The EPR spectra for formyl and methyl radicals were simulated from the following parameters for the hyperfine structure, $A$, tensors and $g$-factor tensors: for DCO, $A_{x x}=20.45 \mathrm{G}, A_{y y}=20.97 \mathrm{G}, A_{z z}=21.86 \mathrm{G}$, $A_{y z}=0.89 \mathrm{G}, g_{x}=2.0033, g_{y}=2.0019, g_{z}=1.9952$, a linewidth of $0.9 \mathrm{G}$ and a mixture of 1:1 Gaussian to Lorentzian lines were assumed (see also Adrian et al. 1962); for $\mathrm{CD}_{3}, A_{x x}=A_{y y}=A_{\perp}=3.62 \mathrm{G}, A_{z z}=A_{\|}=$ $3.42 \mathrm{G}, g_{x}=g_{y}=g_{\perp}=2.0026, g_{z z}=g_{\|}=2.0022$ 

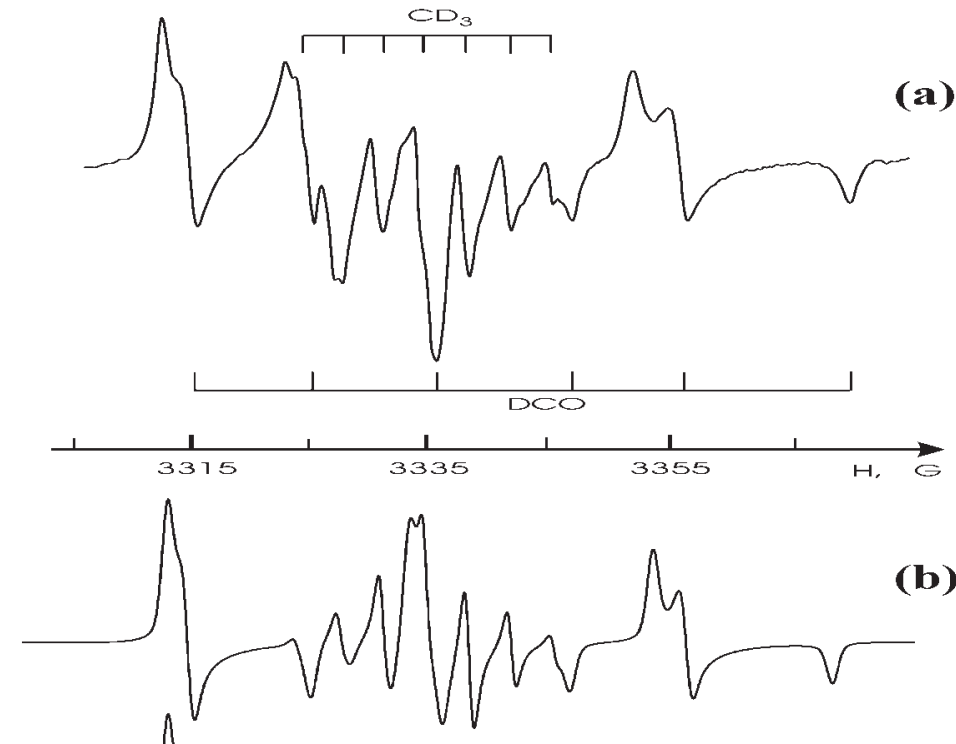

3335

Fig. 3. a) The EPR spectrum of DCO and $\mathrm{CD}_{3}$ free radicals formed in a sequence of gas-grain D-atom addition reactions in solid $\mathrm{CO}$ at $4.2 \mathrm{~K}$. The EPR resonance frequency $f_{\text {res }}=$ $9345.66 \mathrm{MHz}$. b) The simulated EPR spectrum of the free radical mixture of $\mathrm{DCO}$ and $\mathrm{CD}_{3}$ trapped in solid CO. c) The simulated EPR spectrum of DCO radical trapped in solid $\mathrm{CO}$, which is one component to contribute to the composite twocomponent spectrum b). d) The simulated EPR spectrum of $\mathrm{CD}_{3}$ radical trapped in solid $\mathrm{CO}$ which is the second component of the spectrum b). In the simulation EPR resonance frequency was taken equal 9345.7 MHz. The simulation parameters are given in the text.

and a linewidth of $0.75 \mathrm{G}$ and Lorentzian line shape were assumed. The best fit of the simulated curve (b) is obtained from a concentration of $\mathrm{CD}_{3}$ radical of about $1 \%$ of the DCO concentration in solid CO. After the sample condensation was completed, repeated registration of the EPR spectra of samples at fixed temperatures 1.5-4.2 K showed no changes in the spectra like those depicted in Figs. 2a and 3a for several hours. Thus, no reactions of type (1) occur in the sample in the above temperature range with no flow of $\mathrm{CO}$ molecules and $\mathrm{H}$ or $\mathrm{D}$ atoms from the gas phase. In that case, the concentrations of methyl and ethyl radicals in the sample did not change noticeably for hours at least.

Thus, the present results provide further direct support for the gas-grain Seq. (1).

The above results allow the suggestion to be made that $\mathrm{HCO}$ and $\mathrm{CH}_{3}$ radicals may accumulate in large concentrations in interstellar gas grains, cometary ices and planetary atmospheres. The optical spectra of the free radicals $\mathrm{HCO}$ and $\mathrm{CH}_{3}$ are well know (Bernstein et al. 1995; Gerakines et al. 1996). It may be beneficial to study in the laboratory the optical spectra of these radicals together with the EPR spectra in various matrices of astrophysical interest. Observation of these radicals and an estimate of their concentration in the interstellar medium will provide important information on the transformation of inorganic molecules to organic ones in space conditions.

\section{Low-temperature reactions between the $\mathrm{CH}_{4}$ gaseous discharge products trapped in the solid $\mathrm{CH}_{4}$ matrix}

Methane $\left(\mathrm{CH}_{4}\right)$ and ethane $\left(\mathrm{C}_{2} \mathrm{H}_{6}\right)$ have been found in comets and in the atmospheres of several solar planets. The observation of saturated hydrocarbons either frozen on grains or as gases, provides strong evidence that the reactions on dust grains play an important role in the interstellar chemical evolution. To explain the high $(>0.5)$ $\mathrm{C}_{2} \mathrm{H}_{6} / \mathrm{CH}_{4}$ ratio in comets, a mechanism was proposed of $\mathrm{CH}_{4}$ conversion into $\mathrm{C}_{2} \mathrm{H}_{6}$ through the production of $\mathrm{C}_{2} \mathrm{H}_{6}$ in icy grain mantles in the clouds of origin either by photolysis of $\mathrm{CH}_{4}$-rich ice (Gerakines et al. 1996; Hiraoka et al. 1999) or by hydrogen-addition reaction to $\mathrm{C}_{2} \mathrm{H}_{2}$ condensed from the gas phase (Hiraoka et al. 1999; Sandford et al. 2000). Other pathways of the formation of $\mathrm{C}_{2} \mathrm{H}_{6}$ molecules trapped in the solid $\mathrm{CH}_{4}$ matrix through the gas-grain processes are discussed here. Using the EPR technique, we studied low-temperature reactions in the solid $\mathrm{CH}_{4}$ of the products of gaseous discharge in $\mathrm{CH}_{4}$.

Figure 4 shows an EPR spectrum of the sample obtained by $30 \mathrm{~min}$ condensation of $\mathrm{CH}_{4}$ gas from channel A onto a substrate at $4.2 \mathrm{~K}$ together with the discharge products formed in the channel (Fig. 1). During this process, no gas flow was fed through channel B. In turn, the gas flux from channel $\mathrm{A}$ was set at minimum so as to make 


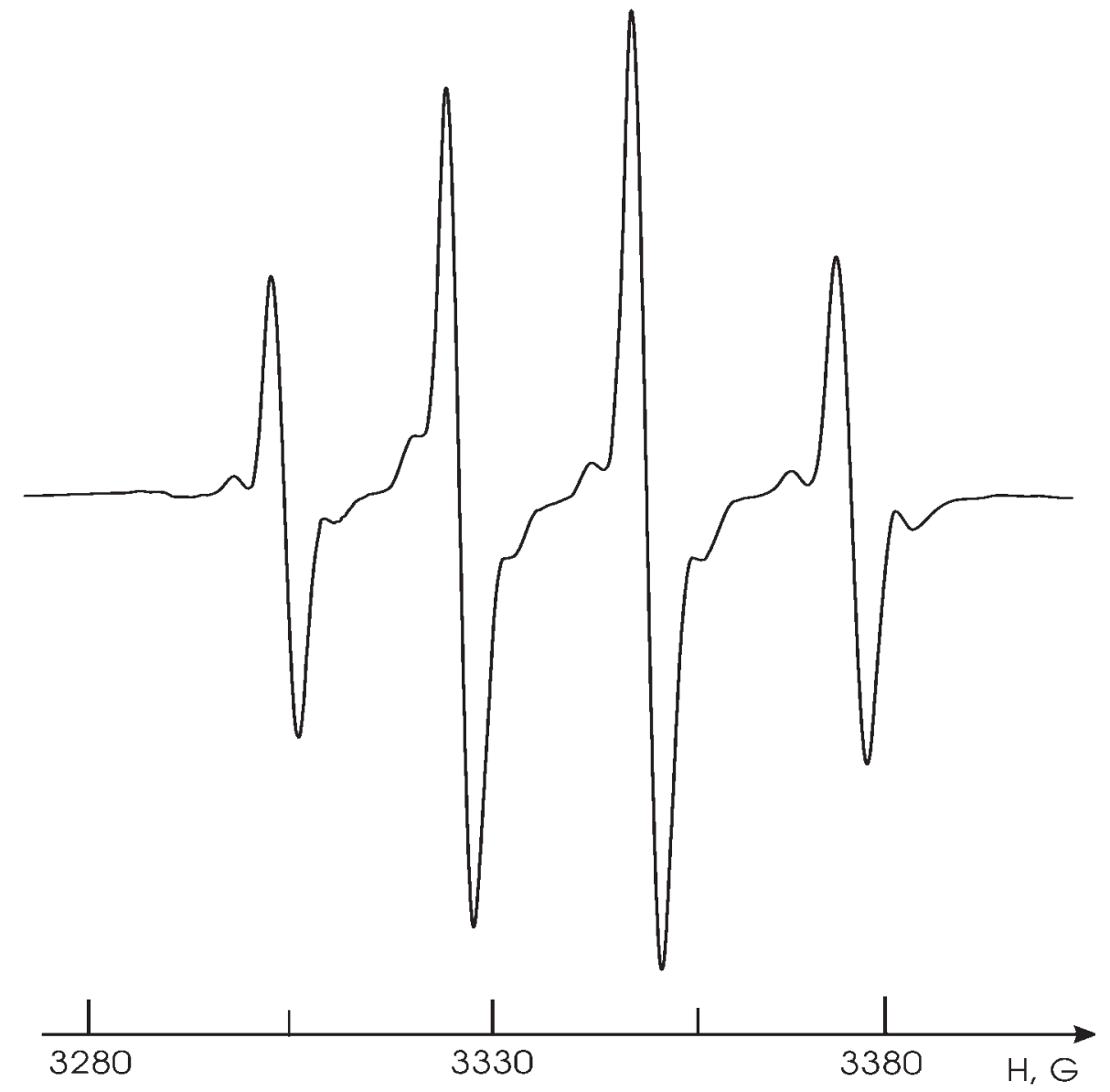

Fig. 4. EPR spectrum of $\mathrm{CH}_{3}$ free radicals trapped at $4.2 \mathrm{~K}$ in $\mathrm{CH}_{4}$ matrix which form under condition of small gas flow fed through the gas discharge onto the substrate. EPR resonance frequency $f_{\text {res }}=9355.22 \mathrm{MHz}$. it possible for the discharge to be operated. Examining Fig. 4, one can see only four-component spectrum which is characteristic of $\mathrm{CH}_{3}$ radical in a $\mathrm{CH}_{4}$ matrix and well studied by photolysis (Adrian et al. 1985). In the present experiment, $\mathrm{CH}_{3}$ radicals are formed in the gas discharge through dissociation of part of the $\mathrm{CH}_{4}$ molecules:

$$
\mathrm{CH}_{4} \rightarrow \mathrm{CH}_{3}+\mathrm{H} \text {. }
$$

The $\mathrm{CH}_{3}$ radicals are subsequently trapped in solid $\mathrm{CH}_{4}$. These records showed no EPR spectrum of hydrogen atoms. In the next experiment, two flows were simultaneously incident onto the substrate at the same substrate temperature of $4.2 \mathrm{~K}$ : one with the gas discharge products from channel A, with a flux matching that of the previous experiment, and the other of pure $\mathrm{CH}_{4}$, an order of magnitude greater, from channel B. The EPR spectrum obtained after $30 \mathrm{~min}$ condensation is shown in Fig. 5a. This spectrum differs from that in Fig. 4 and matches the well-known spectrum of $\mathrm{C}_{2} \mathrm{H}_{5}$ ethyl radical (Cochran et al. 1970; Toriyama et al. 1979). It is reasonable to suppose that the spectrum in Fig. 5a is actually the sum of two spectra: for $\mathrm{CH}_{3}$ and $\mathrm{C}_{2} \mathrm{H}_{5}$ radicals. By computer simulation (Toriyama et al. 1979), the spectrum could be matched assuming a ratio $\mathrm{C}_{2} \mathrm{H}_{5}$ to $\mathrm{CH}_{3}$ of 7 to 3 (Fig. $5 \mathrm{~b}$ ). Figures $5 \mathrm{c}$ and $\mathrm{d}$ show simulated EPR spectra for $\mathrm{C}_{2} \mathrm{H}_{5}$ and $\mathrm{CH}_{3}$ radicals respectively trapped in a polycrystalline solid $\mathrm{CH}_{4}$. These spectra are added to obtain the two component composite spectrum (b). The spectra (c) and (d) for ethyl and methyl radicals were simulated from the following parameters: for $\mathrm{C}_{2} \mathrm{H}_{5}, A_{\|}=A_{z z}=29.0 \mathrm{G}$, $A_{\perp}=A_{x x}=A_{y y}=18.4 \mathrm{G}$ for the $\alpha-\mathrm{H}$ coupling and $A_{\|}=29.2 \mathrm{G}$ and $A_{\perp}=27.4 \mathrm{G}$ for the $\beta$-coupling, the $g$-factor being $g=2.00232$; for $\mathrm{CH}_{3}, A=23.0 \mathrm{G}$ and $g=$ 2.00214 (isotropic spectrum). A Gaussian lineshape with $3.5 \mathrm{G}$ linewidth were assumed. (See also Toriyama et al. 1979.)

Note, that the appearance of a $\mathrm{C}_{2} \mathrm{H}_{5}$ spectrum in the second experiment was matched by the spectrum of hydrogen atoms. The purchased methane gas was of $99.99 \%$ purity.

With condensation at a substrate temperature lower than $4.2 \mathrm{~K}$, the EPR spectrum shows the lines of the $\mathrm{C}_{2} \mathrm{H}_{5}$ radical even at the minimum $\mathrm{CH}_{4}$ flow through channel $\mathrm{A}$ that can be set in the experimental conditions, and with no gas flow through channel B. These experiments yielded $\mathrm{C}_{2} \mathrm{H}_{5}$ lines even at $3.7 \mathrm{~K}$. They became more intense with further decrease of the substrate temperature, $T_{\text {sub }}$. At $T_{\text {sub }}=1.5 \mathrm{~K}$, the spectra were similar to those in Fig. $5 \mathrm{a}$. It turned out that even at $T_{\text {sub }}=4.2 \mathrm{~K}$ and a flow through the channel $\mathrm{A}$ only, the $\mathrm{C}_{2} \mathrm{H}_{5}$ lines may be obtained by merely increasing the flow through channel A. In all cases in which the EPR spectrum of $\mathrm{C}_{2} \mathrm{H}_{5}$ radicals showed up it 

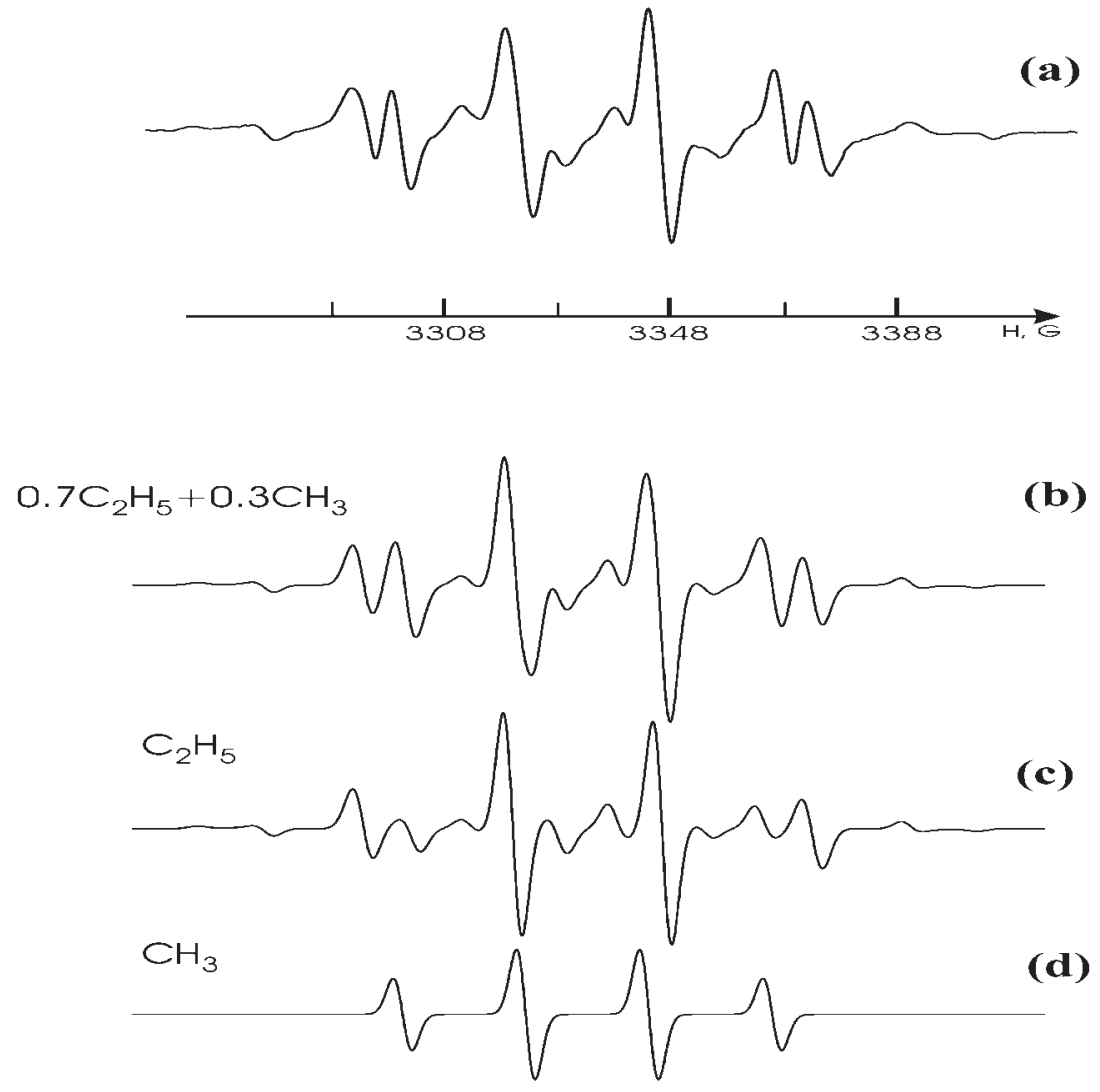

Fig. 5. a) The EPR spectrum of a mixture of $\mathrm{C}_{2} \mathrm{H}_{5}$ and $\mathrm{CH}_{3}$ free radicals formed in a solid $\mathrm{CH}_{4}$ sample that grows at $4.2 \mathrm{~K}$ with an addition of large $\mathrm{CH}_{4}$ gas flow avoiding the discharge zone. $\mathrm{C}_{2} \mathrm{H}_{5}$ forms through reactions between gas discharge products being trapped in solid $\mathrm{CH}_{4}$. The EPR resonance frequency $f_{\text {res }}=9348.75 \mathrm{MHz}$. b) The simulated EPR spectrum of the free radical mixture of $\mathrm{C}_{2} \mathrm{H}_{5}$ and $\mathrm{CH}_{3}$ trapped in solid $\mathrm{CH}_{4}$. The best fit of the simulated curve is obtained from a ratio for the $\mathrm{C}_{2} \mathrm{H}_{5}$ and $\mathrm{CH}_{3}$ contents of 7:3. c) The simulated EPR spectrum of $\mathrm{C}_{2} \mathrm{H}_{5}$ radical trapped in solid $\mathrm{CH}_{4}$, which is one of two components contributing to the composite spectrum b). d) The simulated EPR spectrum of the $\mathrm{CH}_{3}$ radical trapped in solid $\mathrm{CH}_{4}$ which is the second component of spectrum b). The EPR resonance frequency of the simulated spectrum equals 9348.7 MHz. The parameters of the simulation are given in the text. was accompanied by the EPR spectrum of matrix isolated hydrogen atoms.

The obtained results can be interpreted as follows. It seems that most of the products formed in a methane gas discharge, which enter the cold substrate together with $\mathrm{CH}_{4}$ molecules, is composed of hydrogen atoms, $\mathrm{CH}_{3}$ radicals produced by dissociation of $\mathrm{CH}_{4}$ molecules by electron impact, reaction (2), and $\mathrm{C}_{2} \mathrm{H}_{6}$ molecules formed in the discharge. The results of the mass-spectroscopy analysis of the products formed in a pure $\mathrm{CH}_{4}$ gas discharge have been presented by Toyoda et al. (1989), Kojima et al. (1989), Sugai et al. (1990), Sugai \& Toyoda (1992), Dagel et al. (1996). For a 5-25 W radio-frequency discharge with a plasma temperature of about $400 \mathrm{~K}$ and a low $\mathrm{CH}_{4}$ pressure of $\sim 0.005-0.02$ Torr, the concentrations of the discharge products were found to be $\left[\mathrm{CH}_{3}\right]=(2.5-$ 4.7) $\times 10^{11} \mathrm{~cm}^{-3},\left[\mathrm{C}_{2} \mathrm{H}_{6}\right]=10^{11}-10^{12} \mathrm{~cm}^{-3},\left[\mathrm{CH}_{2}\right] \sim$ $10^{9} \mathrm{~cm}^{-3}$, while, the $[\mathrm{H}]$ value was estimated not to exceed $10^{13} \mathrm{~cm}^{-3}$. It was also verified that at low pressures the electron impact dissociation of $\mathrm{CH}_{4}$ molecules, reaction (2), was the major mechanism for producing $\mathrm{CH}_{3}$ radicals. It turned out that at a $\mathrm{CH}_{4}$ pressure in the discharge above 0.06 Torr, the $\mathrm{CH}_{4}^{+}+\mathrm{CH}_{4} \rightarrow \mathrm{CH}_{3}+\mathrm{C}_{2} \mathrm{H}_{5}^{+}$ ion-molecule reaction started to dominate the production of $\mathrm{CH}_{3}$ and at higher pressure (>0.1 Torr) $\mathrm{CH}_{3}$ radicals were produced almost exclusively by this process. At a
$\mathrm{CH}_{4}$ pressure of 0.3 Torr and $10 \mathrm{~W} \mathrm{RF}$ power supplied to the discharge, the $\mathrm{CH}_{3}$ density averaged over the discharge volume was estimated to be $\sim(6-7) \times 10^{11} \mathrm{~cm}^{-3}$ (Sugai et al. 1990). The major loss channel of $\mathrm{CH}_{3}$ radicals is due to the three-particle reaction of the radical recombination with participation of a $\mathrm{CH}_{4}$ molecule:

$\mathrm{CH}_{3}+\mathrm{CH}_{3}+\left(\mathrm{CH}_{4}\right) \rightarrow \mathrm{C}_{2} \mathrm{H}_{6}+\left(\mathrm{CH}_{4}\right)$.

The same reaction, (3), is the major source of $\mathrm{C}_{2} \mathrm{H}_{6}$ molecules depleted through the electron collision dissociation:

$\mathrm{C}_{2} \mathrm{H}_{6} \rightarrow \mathrm{C}_{2} \mathrm{H}_{5}+\mathrm{H}$.

The $\mathrm{C}_{2} \mathrm{H}_{5}$ density in the discharge seems to be very low because unlike the $\mathrm{CH}_{3}$ radical, the $\mathrm{C}_{2} \mathrm{H}_{5}$ radical possesses a high sticking probability and the principal fate of $\mathrm{C}_{2} \mathrm{H}_{5}$ appears to be surface loss through reactions with other free radicals and $\mathrm{H}$-atoms from the discharge (Dagel et al. 1996).

In the present study, the $\mathrm{CH}_{4}$ pressure in discharge was set to a value of the order of several Torrs, i.e. several times as great as in the cited papers by Toyoda et al. (1989), Kojima et al. (1989), Sugai et al. (1990), Sugai \& Toyoda (1992), and Dagel et al. (1996). It is hard to predict how such an increase in the $\mathrm{CH}_{4}$ pressure would alter the $\mathrm{C}_{2} \mathrm{H}_{6}$ density in the gas discharge, since the rising 
$\mathrm{CH}_{4}$ base pressure is expected to increase the probability of the three-particle reaction, (3), with a greater yield of $\mathrm{C}_{2} \mathrm{H}_{6}$. On the other hand, this increases the probabilities of the $\mathrm{C}_{2} \mathrm{H}_{6}$ dissociation in reaction (4) due to the higher electron concentration, and also of the three-particle recombination $\mathrm{CH}_{3}+\mathrm{H}+\left(\mathrm{CH}_{4}\right) \rightarrow \mathrm{CH}_{4}+\left(\mathrm{CH}_{4}\right)$ which competes with reaction (3). The most significant difference, though, between our methane discharge and those of Toyoda et al. (1989), Kojima et al. (1989), Sugai et al. (1990), Sugai \& Toyoda (1992), Dagel et al. (1996) is that the walls of the discharge tube in the present study were cooled with liquid nitrogen vapor of about $120 \mathrm{~K}$, while in the cited papers the walls were at temperatures of $300-$ $400 \mathrm{~K}$. At $120 \mathrm{~K}$, the saturated $\mathrm{C}_{2} \mathrm{H}_{6}$ vapor pressure is about a factor of $1.25 \times 10^{4}$ lower than the pressure at $300 \mathrm{~K}$. This implies that the sticking probability on the $120 \mathrm{~K}$ walls of a gas discharge tube is far above that on the $300-400 \mathrm{~K}$ walls. An estimate shows that the $\mathrm{C}_{2} \mathrm{H}_{6}$ density would decrease with the increase of the sticking coefficient. Such a low wall temperature of the discharge tube would, therefore, reduce the relative concentration of $\mathrm{C}_{2} \mathrm{H}_{6}$ molecules in our methane discharge with the $\mathrm{CH}_{4}$ density estimated to be about $(3-6) \times 10^{16} \mathrm{~cm}^{-3}$.

Apart from the trapping of $\mathrm{C}_{2} \mathrm{H}_{6}$ molecules coming from the gas discharge onto the sample, ethane molecules may form during the condensation, onto the sample surface, of the $\mathrm{CH}_{4}$ flow which has passed through the discharge and contains methyl radicals which may take part in reaction (3). A contribution to this surface reaction is expected from those $\mathrm{CH}_{3}$ radicals which meet before loosing their mobility and becoming matrix-isolated. $\mathrm{C}_{2} \mathrm{H}_{6}$ molecules thus formed are expected to be trapped more easily in the matrix than $\mathrm{CH}_{3}$ radicals. It is hard to assess, at present, the quantity of matrix-isolated ethane molecules produced by the above process. Finally, the $\mathrm{C}_{2} \mathrm{H}_{6}$ molecules trapped in the matrix can form through the photolysis of the parent $\mathrm{CH}_{4}$ molecules due to UV radiation from the gas discharge (this process has been described by Gerakines et al. 1996). The contribution of this process is, however, likely to be small under the present experimental conditions because of the weak discharge used and the low radiation intensity.

It follows from the above discussion that in our experiments, the sample of solid $\mathrm{CH}_{4}$ being condensed onto the substrate at $1.5-4.2 \mathrm{~K}$ preferably traps $\mathrm{CH}_{3}$ radicals, $\mathrm{H}$-atoms, $\mathrm{C}_{2} \mathrm{H}_{6}$ molecules, and a small amount of other molecules, like $\mathrm{C}_{m} \mathrm{H}_{n}$. The link between the processes described and the experimental results can be verified by considering the EPR spectrum in Fig. 4. It shows that, under certain conditions, matrix isolation of $\mathrm{CH}_{3}$ radicals may occur while neither $\mathrm{C}_{2} \mathrm{H}_{5}$ radicals nor hydrogen atoms are trapped. The matrix isolation of hydrogen atoms is discussed below. It must also be stressed that Fig. 4 suggests that no appreciable amount of $\mathrm{C}_{2} \mathrm{H}_{5}$ radicals comes from the discharge onto the growing sample; otherwise this radical should be visible in Fig. 4, because heavy $\mathrm{C}_{2} \mathrm{H}_{5}$ radicals are expected to be trapped with no less efficiency than light $\mathrm{CH}_{3}$ radicals.
In our experiments, $\mathrm{C}_{2} \mathrm{H}_{5}$ radicals matrix-isolated in the $\mathrm{CH}_{4}$ solid (Fig. 5a) can be assumed to form as follows. The surface layer of the growing sample must include mobile hydrogen atoms that have come from the discharge as a product of dissociation reaction (2). These highly mobile hydrogen atoms travel for long distances in the surface layer and, encountering immobilized $\mathrm{C}_{2} \mathrm{H}_{6}$ molecules, they abstract an H-atom through the well-known abstraction reaction (Toriyama et al. 1979; Adrian et al. 1994):

$$
\mathrm{C}_{2} \mathrm{H}_{6}+\mathrm{H} \rightarrow \mathrm{C}_{2} \mathrm{H}_{5}+\mathrm{H}_{2} \text {. }
$$

When both the concentration of $\mathrm{H}$ atoms and their mobility in the surface layer are high enough, abstraction reaction (5) may appreciably contribute to the yield of matrix-isolated $\mathrm{C}_{2} \mathrm{H}_{5}$ radicals. Matrix-isolated $\mathrm{C}_{2} \mathrm{H}_{5}$ radicals formed in this way, as well as trapped $\mathrm{CH}_{3}$ radicals become visible in the EPR spectrum shown in Fig. 5a. The above gas-grain reactions should be of considerable importance in the interstellar medium.

Thus, we conclude that the rate of formation of matrixisolated ethyl radicals can be defined as

$\frac{\mathrm{d}\left[\mathrm{C}_{2} \mathrm{H}_{5}\right]}{\mathrm{d} t}=k_{\mathrm{r}}^{\prime}\left[\mathrm{H}_{\mathrm{r}}\right]\left[\mathrm{C}_{2} \mathrm{H}_{6}\right]$.

Here, $\left[\mathrm{C}_{2} \mathrm{H}_{6}\right]$ is the ethane molecule concentration in the sample, which seems to be independent of the substrate temperature. An EPR spectrum of $\mathrm{CH}_{4}$ matrix-isolated $\mathrm{C}_{2} \mathrm{H}_{5}$ radicals formed in reaction (5) similar to that in Fig. 5 was reported earlier by Toriyama et al. (1979) and Bhattacharia et al. (1981). They observed the radical formation with a molecular ethane impurity in $\mathrm{CH}_{4}$ of $0.5-0.8 \%$. A sample of $\mathrm{CH}_{4}$ solid was $\gamma$-irradiated at $4.2 \mathrm{~K}$. The subsequent temperature rise detrapped hydrogen atoms which migrated through the crystal to encounter ethane molecules and abstract a hydrogen atom, thus forming ethyl radicals. Turning to Eq. $(6),\left[\mathrm{H}_{\mathrm{r}}\right]$ is the density of hydrogen atoms in the surface layer of our sample which are mobile enough to participate in reaction (5). The conditions that have an effect on the density of such atoms will be discussed below. Bhattacharya et al. (1981) found that the $\mathrm{H}$-atoms trapped in $\mathrm{CH}_{4}$ and $\mathrm{CD}_{4}$ matrices become largely immobilized below $12 \mathrm{~K}$. The rate constant, $k_{\mathrm{r}}^{\prime}$, is unavailable in the literature. This constant seems to depend on the diffusion coefficient, $D_{\mathrm{H}}$, of hydrogen atoms at the solid $\mathrm{CH}_{4}$ surface, as well as on its temperature. It follows from the obtained results, however, that the $\mathrm{C}_{2} \mathrm{H}_{5}$ yield may vary considerably in the narrow temperature range from 4.2 to $3.7 \mathrm{~K}$, where $k_{\mathrm{r}}^{\prime}$ may be taken to be constant. Thus, the relationship between the $\mathrm{C}_{2} \mathrm{H}_{5}$ yield and experimental conditions we observed relates to a change in the $\left[\mathrm{H}_{\mathrm{r}}\right]$ quantity, i.e. this yield is supposedly governed by the density of hydrogen atoms which remain mobile long enough to encounter and react with trapped $\mathrm{C}_{2} \mathrm{H}_{6}$ molecules. Bhattacharya et al. (1981) found that below $12 \mathrm{~K}$ the trapped H-atoms in solid $\mathrm{CH}_{4}$ do not decay significantly over many minutes. They observed that the trapped $\mathrm{H}$ atoms in $\mathrm{CH}_{4}$ could react with captured $\mathrm{C}_{2} \mathrm{H}_{6}$ to form $\mathrm{C}_{2} \mathrm{H}_{5}$ when the temperature 
was increased above $12 \mathrm{~K}$. Consider the phenomena affecting the density, $\left[\mathrm{H}_{\mathrm{r}}\right]$, of mobile atoms. Let us write the product, $k_{\mathrm{r}}^{\prime}\left[\mathrm{H}_{\mathrm{r}}\right]$ as $k_{\mathrm{r}}[\mathrm{H}]$, i.e. $k_{\mathrm{r}}^{\prime}\left[\mathrm{H}_{\mathrm{r}}\right]=k_{\mathrm{r}}[\mathrm{H}]$, where $[\mathrm{H}]$ is the surface density of hydrogen atoms, and the ratio, $k_{\mathrm{r}} / k_{\mathrm{r}}^{\prime}=\left[\mathrm{H}_{\mathrm{r}}\right] /[\mathrm{H}]$, is for that portion of the atoms which participates in reaction (5). In the steady state, the surface density of hydrogen atoms may be found from the following equality:

$$
\begin{aligned}
I_{\mathrm{H}}= & k_{\mathrm{d}}[\mathrm{H}]+k_{0}[\mathrm{H}]^{2}+k_{\mathrm{t}}[\mathrm{H}]+k_{\mathrm{r} 1}[\mathrm{H}]\left[\mathrm{CH}_{3}\right] \\
& +k_{\mathrm{r}}[\mathrm{H}]\left[\mathrm{C}_{2} \mathrm{H}_{6}\right]=\text { const. }
\end{aligned}
$$

Here, $I_{\mathrm{H}}$ is the flux of free hydrogen atoms from the gas discharge onto the unit sample surface per unit time. On the right hand side of Eq. (7), the first term represents the loss of $\mathrm{H}$ atoms through desorption, the second term reflects the recombination of hydrogen atoms with each other, the third represents the matrix isolation of $\mathrm{H}$ atoms, the forth stands for the recombination of hydrogen atoms and methyl radicals: $\mathrm{CH}_{3}+\mathrm{H}=\mathrm{CH}_{4}$, and the fifth stands for the loss of $\mathrm{H}$ atoms in abstraction reaction (5) with ethane molecules. Thermalized hydrogen atoms in the ground state are known to be nonreactive with $\mathrm{CH}_{4}$ molecules, i.e. with the matrix molecules in the present study.

Expressions (6) and (7) make it possible to account for the dependence of the yield of ethyl radicals (see the last term of expression (7)) on the variation of our experimental conditions, in particular, on the substrate temperature and matrix flux. It stems from the above discussion that the change in the $\mathrm{C}_{2} \mathrm{H}_{5}$ radical yield matches the change in the quantity of "active" hydrogen atoms $\mathrm{H}_{\mathrm{r}}$ (i.e. those participating in reaction (5)), which contribute to the last term of Eq. (7). At a constant rate of the hydrogen flow onto the sample surface, $I_{\mathrm{H}}=$ const., $\left[\mathrm{H}_{\mathrm{r}}\right] /[\mathrm{H}]$ varies with the sample temperature, depending on the change in the coefficients $k_{\mathrm{d}}, k_{0}, k_{\mathrm{t}}$, and $k_{\mathrm{r} 1}$. Decreasing any of these coefficients would increase the yield of $\mathrm{C}_{2} \mathrm{H}_{5}$ and vice versa. As the substrate temperature is lowered, $k_{\mathrm{d}}$ becomes smaller: $k_{\mathrm{d}}=k_{\mathrm{d}}^{0} \exp \left(-E_{\mathrm{d}} / k T\right)$. Here, $E_{\mathrm{d}}$ is the activation energy for the desorption of hydrogen atoms from the surface of the sample growing from the gas phase, and $k$ is the Boltzmann constant. The recombination rate constant, $k_{0}$, would also decrease following a decrease in the mobility of hydrogen atoms. At the same time, lowering the temperature would presumably give rise to matrix isolation coefficient, $k_{\mathrm{t}}$, of the hydrogen atoms, which would lower $\left[\mathrm{H}_{\mathrm{r}}\right]$. The contribution of the two last terms of expression (7) to the variation of $\left[\mathrm{H}_{\mathrm{r}}\right]$ seems to be smaller than that of the first terms presumably because of a weaker dependence of $k_{\mathrm{r} 1}$ and $k_{\mathrm{r}}$ on the temperature and on the finite concentration of $\left[\mathrm{CH}_{3}\right]$ and $\left[\mathrm{C}_{2} \mathrm{H}_{6}\right]$. For these reasons, the temperature decrease (down from $4.2 \mathrm{~K}$ in our runs) should be followed by a change in the $\left[\mathrm{H}_{\mathrm{r}}\right]$ density and, hence, in the $\mathrm{C}_{2} \mathrm{H}_{5}$ yield. A major part may also be played by the first term, since the coefficient $k_{\mathrm{d}}$ varies exponentially with the temperature. This would increase the yield of $\mathrm{C}_{2} \mathrm{H}_{5}$ radicals in reaction (5). At a higher temperature a large $k_{\mathrm{d}}$ keeps the steady state concentration,
$[\mathrm{H}]$ on the solid surface quite low. With a decrease of temperature, $k_{\mathrm{d}}$ decreases exponentially, increasing $[\mathrm{H}]$ on the sample surface. This is probably why the $\mathrm{C}_{2} \mathrm{H}_{5}$ yield is increased with a substrate temperature decrease and why no EPR signal is obtained of $\mathrm{C}_{2} \mathrm{H}_{5}$ and $\mathrm{H}$ atoms in the spectra in Fig. 4, taken at $4.2 \mathrm{~K}$ with a small $\mathrm{CH}_{4}$ flux onto the substrate. The appearance of trapped $\mathrm{C}_{2} \mathrm{H}_{5}$ radicals at $4.2 \mathrm{~K}$ following the increase in the matrix $\mathrm{CH}_{4}$ flux onto the substrate is probably due to a decrease of the $\mathrm{H}$ atom desorption from the surface because of the higher matrix gas pressure near the surface. Thus, the reactions discussed are governed by the conditions in the surface layer of the sample being condensed from the gas phase, i.e. by an existence or absence of a sufficient concentration of mobile hydrogen atoms, $\left[\mathrm{H}_{\mathrm{r}}\right]$, (expression (6)) which have enough time to participate in reaction (5). A further detailed study of these processes including, perhaps, a quantitative assessment of the experimental relations is being planned by increasing the substrate temperature above $4.2 \mathrm{~K}$ and utilizing other techniques for the sample preparation.

It is worth noting that Hiraoka et al. (1999, 2000) failed to detect the $\mathrm{C}_{2} \mathrm{H}_{5}$ radicals when $\mathrm{H}$-atoms were sprayed over solid $\mathrm{C}_{2} \mathrm{H}_{2}, \mathrm{C}_{2} \mathrm{H}_{4}$ and $\mathrm{C}_{2} \mathrm{H}_{6}$ films at $10-13 \mathrm{~K}$, i.e. no low-temperature reactions of $\mathrm{H}$-atom addition to $\mathrm{C}_{2} \mathrm{H}_{4}$ molecule and $\mathrm{H}$-atom abstraction from $\mathrm{C}_{2} \mathrm{H}_{6}$ molecule were observed. In these runs they tried to detect $\mathrm{C}_{2} \mathrm{H}_{5}$ radicals by thermal desorption mass-spectrometry and Fourier transform- infrared (FT-IR) spectrometry. It seems likely that, with the former technique, $\mathrm{C}_{2} \mathrm{H}_{5}$ radicals may be lost in chemical reactions induced by the heating used for sample desorption, while the latter technique is insufficiently sensitive to these radicals. The EPR technique utilized here to study free radicals in gas-grain reactions may be considered as most promising.

\section{References}

Adrian, F. J., Cochran, E. L., \& Bowers, V. A. 1962, J. Chem. Phys., 36, 1661

Adrian, F. J., Kim, B. F., \& Bohandy, J. 1985, J. Chem. Phys., 82,1804

Adrian, F. J., Bohandy, J., \& Kim, B. F. 1994, J. Chem. Phys., 100,8010

Bernstein, M. P., Sandford, S. A., Allamandola, L. J., \& Chang, Sh. 1995, ApJ, 454, 327

Bhattacharia, D., Wang, H.-Y., \& Willard, J. E. 1981, J. Phys. Chem., 85, 1310

Cochran, E. L., Adrian, F. J., \& Bowers, V. A. 1970, J. Phys. Chem., 74, 2083

Cradock, S., \& Hinchcliffe, A. 1975, Matrix isolation (Cambridge Univ. Press, Cambridge)

Dagel, D. J., Mallouris, C. M., \& Doile, J. R. 1996, J. Appl. Phys., 79, 8735

Ehrenfreund, P., Boogert, A. C. A., Gerakines, P. A., et al. 1996, A\&A, 315, L341

Ehrenfreund, P., Boogert, A. C. A., Gerakines, P. A., Tielens, A. G. G. M., \& van Dishoeck, E. F. 1997, A\&A, 328, 649

Ehrenfreund, P., Kerkhof, O., Schutte, W. A., et al. 1999, A\&A, 350, 240 
Gerakines, P. A., Shutte, W. A., Greenberg, J. M., \& van Dishoeck, E. F. 1995, A\&A, 296, 810

Gerakines, P. A., Schutte, W. A., \& Ehrenfreund, P. 1996, A\&A, 312, 289

Gerakines, P. A., Moore, M. H., \& Hudson, R. L. 2000, A\&A, 357,793

Hiraoka, K., Yamashita, A., Yachi, Y., et al. 1995, ApJ, 443, 363

Hiraoka, K., Miyagoshi, T., Takayama, T., Yamamoto, K., \& Kihara, Y. 1998, ApJ, 498, 710

Hiraoka, K., Yamamoto, K., Kihara, Y., Takayama, T., \& Sato, T. 1999, ApJ, 514, 524

Hiraoka, K., Takayama, T., Euchi, A., Handra, H., \& Sato, T. 2000, ApJ, 532, 1029

Kojima, H., Toyoda, H., \& Sugai, H. 1989, Appl. Phys. Lett., 55,1292

Pendelton, Y. J., Tielens, A. G. G. M., Tokunaga, A. T., \& Bernstein, M. P. 1999, ApJ, 513, 294
Sandford, S. A., Bernstein, M. P., Allamandola, L. J., Gillette, J. S., \& Zare, R. N. 2000, ApJ, 538, 691

Schutte, A., Bassi, D., Tommasini, F., et al. 1976, J. Chem. Phys., 64, 4135

Sugai, H., Kojima, H., Ishida, A., \& Toyoda, H. 1990, Appl. Phys. Lett., 56, 2616

Sugai, H., \& Toyoda, H. 1992, J. Vac. Technol., A10, 1193

Toriyama, K., Iwasaki, M., \& Nunome, K. 1979, J. Chem. Phys., 71, 1698

Toyoda, H., Kojima, H., \& Sugai, H. 1989, Appl. Phys. Lett., 54,1507

Toyoda, H., \& Sugai, H. 1989, Appl. Phys. Lett., 55, 1292

Zhitnikov, R. A., \& Dmitriev, Yu. A. 1994, J. Phys.: Condens. Matter, 6, 2727

Zhitnikov, R. A., \& Dmitriev, Yu. A. 1995, Appl. Magnetic Res., 8, 457 